Reprod. Nutr. Dévelop., 1988, 28 Suppl. n 1, 65-66

\title{
Effet du mode d'incorporation du sérum de luzerne sur la digestibilité et l'activité microbienne dans le rumen
}

\author{
Aicha FASSIH, Catherine CORDELET, F. FAURIE, J. L. TISSERAND
}

Laboratoire de Recherches de la Chaire de Zootechnie ENSSAA-I.N.R.A., 26, boulevard Docteur-Petitjean, 21000 Dijon, France.

Summary. The extraction of protein from lucerne produces some liquid residue (called lucerne serum), the effects of which on rumen microbial activity were studied in 6 adult fistulated wethers. The introduction of the serum directly into the rumen stimulated cellulolytic activity whereas its incorporation into the lucerne solid residue before dehydratation seemed to have no effect.

L'extraction des protéines de luzerne laisse des sous-produits, le sérum et la pulpe, encore appelée «tourteau de luzerne ». Le sérum peut être réintroduit dans le «tourteau de luzerne» avant déshydratation et agglomération. Pour évaluer l'intérêt de cette addition et voir si la déshydratation modifie l'effet du sérum sur l'activité microbienne dans le rumen, nous avons comparé deux rations à base de " tourteau de luzerne» contenant ou non du sérum avec, dans ce dernier cas, introduction du sérum liquide directement dans le rumen.

Matériel et méthodes. Sur six moutons mâles castrés adultes pesant environ $60 \mathrm{~kg}$ et porteurs d'une canule du rumen, nous avons expérimenté pendant deux périodes successives de 40 jours ( 20 jours d'accoutumance, 10 jours de mesure de bilan digestif et de rétention azotée, 10 jours de mesure de l'activité microbienne dans le rumen) deux régimes constitués (par tête et par jour) : soit de $600 \mathrm{~g}$ de « tourteau de luzerne » granulé contenant $20 \%$ de sérum, $200 \mathrm{~g}$ de paille de blé et $200 \mathrm{~g}$ d'orge, soit de $480 \mathrm{~g}$ de « tourteau de luzerne » granulé sans sérum, $200 \mathrm{~g}$ de paille et $200 \mathrm{~g}$ d'orge et de $120 \mathrm{~g}$ de sérum liquide introduit dans le rumen ( $60 \mathrm{~g}$ à chaque repas). Les animaux reçoivent deux repas égaux par jour et disposent de pierre à lécher et d'eau à volonté. Les rations, compte tenu de l'apport du sérum introduit dans le rumen pour la seconde, contiennent respectivement : 90,1 et $90,3 \%$ de matière organique (MO), 11,2 et 11,8\% de matière azotée (MAT) et 28,6 et $25,7 \%$ de cellulose brute (CB).

Nous avons mesuré la digestibilité et le bilan $\mathrm{N}$, la dégradation de la paille in sacco (tissu F100 à deux compartiments de $7 \times 7 \mathrm{~cm}$ avec $2 \mathrm{~g}$ de fourrage par compartiment), après $48 \mathrm{~h}$ de séjour dans le rumen (4 répétitions par mouton soit 24 résultats par traitement) et analysé le contenu du rumen prélevé le matin à jeun ( 2 répétitions par mouton soit 12 résultats par traitement).

Résultats et discussion. Par rapport à l'incorporation du sérum dans le "tourteau de luzerne", l'introduction directe dans le rumen ne modifie pas significativement la digestibilité (MO, CB, MAT) (tabl. 1). Elle a toutefois un effet 
positif sur la dégradation de la paille in sacco (tabl. 1), ce qui confirme les résultats obtenus lors de la complémentation des pailles (El Bachty, 1985; Tisserand et al., 1987). L'introduction du sérum dans le rumen diminue le taux d'ammoniac dans le rumen et augmente la quantité d'acides gras volatils totaux (tabl. 1) ; il n'y a pas de modification du pourcentage d'acide acétique et propionique mais une légère augmentation de celui d'acide butyrique. Le bilan azoté est amélioré par l'addition de sérum liquide dans le rumen, par suite de la stimulation de l'activité microbienne, suggérée par l'augmentation de la production d'acides gras volatils et la diminution du taux d'azote ammoniacal. Cette action positive semble disparaître après déshydratation du sérum. Ces résultats confirment les observations de Saleh (1986): l'incorporation du sérum du « tourteau de luzerne » avant déshydratation n'améliore pas la vitesse de croissance de l'agneau.

TABL. 1. - Effet du mode d'administration du sérum de luzerne sur la digestibilité, la rétention azotée de la ration et l'activité microbienne dans le rumen.

\begin{tabular}{|c|c|c|c|}
\hline & $\begin{array}{c}\text { Sérum } \\
\text { dans la ration }\end{array}$ & $\begin{array}{c}\text { Sérum } \\
\text { dans le rumen }\end{array}$ & Signification \\
\hline Digestibilité MO (\%) & $66,2 \pm 0,6$ & $66,2 \pm 2,3$ & NS \\
\hline Digestibilité CB (\%) & $49,7 \pm 2,1$ & $47,1 \pm 4,2$ & NS \\
\hline Digestibilité MAT (\%) & $68,6 \pm 2,0$ & $70,3 \pm 2,7$ & NS \\
\hline Rétention $\mathrm{N}(\mathrm{g} / \mathrm{j}$ ) & $3,7 \pm 0,7$ & $5,7 \pm 2,1$ & $\mathrm{~S}$ \\
\hline $\mathrm{N}$ retenu (\%) $\mathrm{N}$ ingéré & $21,2 \pm 4,7$ & $30,8 \pm 16,6$ & $S$ \\
\hline \multicolumn{4}{|l|}{ Contenu du rumen: } \\
\hline $\mathrm{pH}$ & 6,8 & 6.9 & NS \\
\hline $\mathrm{N} / \mathrm{NH}_{3}(\mathrm{mg} / 100 \mathrm{ml})$ & 17,9 & 13,1 & $\mathrm{~S}$ \\
\hline Acides gras volatils $(m \cdot$ mole $/ l)$ & 48,5 & 58,2 & $\mathrm{~S}$ \\
\hline Dégradation in sacco MS & 34,4 & 40,9 & $\mathrm{~s}$ \\
\hline Dégradation in sacco $\mathrm{CB}$ & 25,4 & 31,5 & $\mathrm{~s}$ \\
\hline
\end{tabular}

En conclusion, le sérum de luzerne en stimulant l'activité microbienne du rumen peut constituer un complément intéressant pour une ration à base de fourrage pauvre. II n'est pas certain que sa réincorporation au «tourteau de luzerne " soit de nature à améliorer la valeur nutritive de ce dernier.

Remerciements. - Nous remercions le groupe France-Luzerne pour l'aide apportée à la réalisation de cette étude.

El Bachty H., 1985. Mémoire de fin d'études, ENSSAA Dijon, 63 p.

Saleh H., 1986. Mémoire de DEA. Univ. Rennes 1, $23 \mathrm{p}$.

Tisserand J. L., Meschy F., Cordelet C., Faurie F., Mazollier J., 1987. Reprod. Nutr. Déve/op., 27. 283-284. 